American Journal of Infectious Diseases 2 (4): 201-203, 2006

ISSN 1553-6203

(C) 2006 Science Publications

\title{
Assessment of Measles Surveillance in Iran during 2004-2007
}

\author{
${ }^{1}$ Mohammad-Arash Ramezani, ${ }^{1}$ Neda Zamani, ${ }^{2}$ Esmaeel Akhtar, ${ }^{2}$ Kamal Heydari \\ ${ }^{2}$ Reza Fadaee-Noubari and ${ }^{1}$ Seyed Reza Eshaghi \\ ${ }^{1}$ Department of Community and Preventive Medicine, Isfahan Medical Sciences University, Iran \\ ${ }^{2}$ Center for Disease Control, Deputy of Health, Isfahan Medical Sciences University, Iran
}

\begin{abstract}
Elimination of measles using vaccination is one of the most important task worldwide. Iran is in the elimination phase of measles and health professionals base surveillance system on reporting of suspected cases. The aim of this study was to evaluate measles surveillance in center of Iran. The epidemiological data was collected from immediate telephone reports and follow up results in CDC of deputy of health in Isfahan medical sciences university. 59 suspected cases were reported and only measles in one 2 years Afghanian girl had been confirmed. The incidence rate of suspected cases was 18 per one million under risk population. The average age of cases was $8 \pm 8.3$ years that varied from 1 to 34 years. Male was more than female and $13.6 \%$ of cases were immigrant. One third of patients did not have any previous vaccination. The mean age was different significantly in three years of assessment. Our finding demonstrated that the measles surveillance is effective in Iran and endemic measles have been eliminated in Iran. The measles cases are immigrant from neighbor countries.
\end{abstract}

Key words: Iran, measles, surveillance, elimination, vaccination

\section{INTRODUCTION}

Measles is a communicable disease that is considered as a major health problem worldwide with nearly 45 million cases and 1 million deaths occurring each year ${ }^{[1]}$. However, because of human is the exclusive reservoir of measles and existing an effective and safe vaccine, it can be eliminated ${ }^{[2]}$. Three World Health Organization (WHO) regions have targeted measles elimination: the American region by the year 2000, the European region by 2007 and the eastern Mediterranean region by $2010^{[3]}$. To achieve this goal, measles elimination programs were developed and are based on strengthening immunization strategies coupled with attentive virological measles surveillance, the latter is required to monitor progress towards elimination goals ${ }^{[4]}$. In Islamic republic of Iran, measles, mumps and rubella as MMR vaccine is in routine immunization program. In Iran children are scheduled to receive the first (MMR) immunization at 12 months of age and second dose is prescribed at 4 to 6 years of age $\mathrm{e}^{[5]}$. In addition, a measles and rubella campaign immunization was done at December 2003 to January 2004 in Iran for young women during reproductive age. This immunization was caused to measles elimination in Iran. The surveillance system during elimination phase is case-based immunization ${ }^{[6]}$. The aim of this study was to assess the effectiveness of measles surveillance in Isfahan in the center of Iran.

\section{MATERIALS AND METHODS}

Setting: Isfahan is one of the important provinces of Iran that has located in center of country. Isfahan spread $107044.3 \mathrm{Km}^{2}$ areas and is covered 3923255 populations by Isfahan Medical Sciences and Health Services University. It is a strategic area in Iran, 400 kilometers far from South of Tehran the capital of Iran and many ethnic groups are resident in $\mathrm{it}^{[7]}$.

Data collection: Suspected cases were reported immediately by telephone from every peripheral district area to CDC of provinces health center. Suspected cases are defined every patient with fever, cough, rhinorrhea, conjunctivitis and special maculopopular rash that have been visited by physician. The epidemiological data including sex, age, nationality, residential area, number of family members and vaccination history were obtained.

After that the health professionals visit the patients and obtain a blood sample and then this blood sample under standardized condition was referred to the
Corresponding Author:
Mohammad-Arash Ramezani, MD, MPH, Department of Community and Preventive Medicine, Isfahan Medical Sciences University, Hezarjarib Street, Isfahan, Iran, Tel: +983117922542 
Central reference virology laboratory to Tehran for detection of measles virus. At the end the laboratory report confirms the measles infection. All data are registered in special form and repot weekly to Health Ministry. Data for this study were obtained from measles data sheet in CDC of Isfahan provinces health center.

Statistical analysis: All data were summarized as mean and standard deviation for continuous variables and as frequency and percentage for categorical variables. The incidence rate was calculated by dividing of suspected and confirmed cased to under infectious risk population that was age $0-45$ years.

We used the $\chi 2$ test for comparison of categorical data; and t-test and analysis of variance (ANOVA) test and Tukey's post hoc test for continuous variables.

All statistical analyses were performed with SPSS software package version 11.5 (SPSS Inc., Chicago, USA) for Windows. The significance level was set at $\mathrm{P}<0.05$.

\section{RESULTS AND DISCUSSION}

There was 59 suspected case of measles that was reported to CDC. Only one case was confirmed measles by laboratory. She was a 2-year Afghanian girls that had immigrated from Afghanistan to one of rural area in Borkhar city in Isfahan province. The incidence rate of suspected cases was 18 per one million under risk population. The average age of cases was $8 \pm 8.3$ years that varied from 1 to 34 years. Table 1 showed the characteristics of suspected patients in province. Male was more than female and $13.6 \%$ of cases was immigrant. One third of patients did not have any previous vaccination. The mean age was different significantly in three years of assessment (Table 2). However, the other variables didn't show any significant difference during three period of evaluation.

Some epidemic of measles were reported from Iran during last year ${ }^{[8-11]}$. These epidemics had high burden of disease for Health sector ${ }^{[6]}$. Thus vaccination due to elimination of measles was the main goal of all WHO members. Measles elimination was done successfully in the most of country in America, Europe and Asia region and coverage of vaccine have achieved up to $95 \%^{[12-24]}$. Although many viruses can present as a febrile-rash illness mimicking measles, particularly in children and in an elimination setting, such as in Iran, when coverage of the MMR vaccine is high, the majority of such cases will not be due to measles. However the immediate report of cases is necessary because the
Table 1: The characteristics of suspected measles cases

\begin{tabular}{lcc}
\hline Variable & Frequency & Percent \\
\hline Sex & 31 & 52.5 \\
Male & 28 & 47.5 \\
Female & 32 & \\
Residential State & 27 & 54.2 \\
Urban & & 45.8 \\
Rural & 51 & \\
Nationality & 5 & 86.4 \\
Iranian & 3 & 8.5 \\
Afghanian & & 5.1 \\
Pakistanian & 20 & 34 \\
Previous vaccination & 16 & 27 \\
Never & 16 & 27 \\
One dose & 7 & 12 \\
Two dose & & \\
Three dose & & \\
\hline
\end{tabular}

Table 2: The mean age of cases in three years evaluation

\begin{tabular}{llll}
\hline Period of time & Number & Mean \pm S.D & F, P value \\
\hline $2004-2005$ & 20 & $5.6 \pm 7.8$ & $\mathrm{~F}=3.297$ \\
$2005-2006$ & 17 & $12.1 \pm 9$ & $\mathrm{P}=0.04$ \\
$2006-2007$ & 22 & $7 \pm 7.3$ & \\
\hline
\end{tabular}

immigration rate in Isfahan is high. Our finding showed the unique case of measles was an immigrant Afghanian girls. The sensitivity of the system is increased through reporting and investigation of all suspected measles cases by means of an inclusive case definition (generalized maculopapular rash and fever) and the specificity is increased through laboratory testing for measles of all suspected cases ${ }^{[25]}$. The CDC and health departments need to continue efforts directed at health care professionals to ensure the recognition, proper diagnostic workup and reporting of measles ${ }^{[26]}$.

It seems that the endemic transmission in Iran was eliminated. Guy and coworkers showed in the USA measles patients was imported to America ${ }^{[27]}$. But surveillance of measles is necessary in Iran. Improvement of the current surveillance in Iran helps health sector and health policy makers that decide to control of disease and reduce burden of measles disease.

\section{REFERENCES}

1. World Health Organization (WHO), 1997. Progress towards global control and elimination, 19901996. Wkly. Epidemiol. Rec., 72: 349.

2. Godoy, P., A. Dominguez and J. Alvarez, 1999. Measles epidemiology in Catalonia (Spain): Implications for a regional vaccination programme. Int. J. Epidemiol., 28: 558.

3. Centers for Disease Control and Prevention (CDC), 1999. Progress towards measles eliminationeastern Mediterranean region, 1980-1998. Wkly. MMWR., 48: 1081. 
4. World Health Organization (WHO), 1999. Measles-progress towards global control and regional elimination, 1998-1999. Wkly. Epidemiol. Rec., 74: 434.

5. Gooya, M.M., S.M. Zahraee, A.R. Esteghamati, M. Salaramoli, F. Abdolo and A. Babaee, 2004. Expanded Program on Immnization. Health Ministry, Tehran, Iran.

6. Esteghamati, A.R., M. Nasr-Dadras, A. Sabouri, M.M. Gooya and S.M. Zahraee, 2004. Guideline for measle surveilance (Elimination Phase). CDC, Deputy of Health, Iran Health Ministry, Tehran, Iran.

7. Management and Planning Organization (MPO), 2005. Statistical year book of Isfahan province2004. Pooyandegan Toseea Co., Isfahan, Iran.

8. Janghorbani, M., M.H. Daie Parizi and K. Ghorbani, 1993. Measles epidemics in Kerman City, Iran. Public Health, 107: 79.

9. Karimi, A., A. Arjomandi, A. Alborzi, M. Rasouli, M.R. Kadivar, B. Obood and B. Pourabbas, 2004. Prevalence of measles antibody in children of different ages in Shiraz, Islamic Republic of Iran. East Mediterr. Health J., 10: 468.

10. Loo, M.K., F. Sabahi, H. Soleimanjdahi, A. Kazemnejad and M.H. Roustai, 2003. Seroprevalence of neutralizing antibodies to measles virus in a vaccinated population in Iran, 1998. Eur. J. Epidemiol., 18: 1085.

11. Mood, B.S., R.N. Naini, M. Salehi, H.R. Kouhpayeh, T.M. Azad and T.N. Poor, 2005. Immunity against measles among vaccinated school going children in Zahedan, southeast of Iran. Indian J. Med. Microbiol., 23: 274.

12. Measles surveillance: El Salvador, 1996. EPI. Newsl., 18: 4.

13. Measles surveillance: Nicaragua, 1996. EPI.Newsl., 18: 4.

14. Anonymous, 1998. Progress toward global measles control and regional elimination, 1990-1997. MMWR Morb. Mortal. Wkly. Rep., 47: 1049.

15. Anonymous, 1999. Global measles control and regional elimination, 1998-1999.. MMWR Morb. Mortal. Wkly. Rep., 48: 1124.

16. Anonymous, 1999. Progress toward measles elimination--Southern Africa, 1996-1998. MMWR Morb. Mortal. Wkly. Rep., 48: 585.
17. Anonymous, 1999. Measles. Progress toward global control and regional elimination, 1990-1998. Can. Commun. Dis. Rep., 25: 37.

18. Anonymous, 2004. Progress toward measles elimination--region of the Americas, 2002-2003. MMWR Morb. Mortal. Wkly. Rep., 53: 304.

19. Anonymous, 2005. Progress toward elimination of measles and prevention of congenital rubella infection--European region, 1990-2004. MMWR Morb. Mortal. Wkly. Rep., 54: 175.

20. Khalil, M.K., Y.Y. Al Mazrou, M.N. AlHowasi and M. Al Jeffri, 2005. Measles in Saudi Arabia: from control to elimination. Ann. Saudi. Med., 25: 324.

21. King, A., P. Varughese, G. De Serres, G.A. Tipples and J. Waters, 2004. Measles elimination in Canada. J. Infect. Dis,. 189 (Suppl. 1): S236.

22. Lambert, S.B., H.A. Kelly, R.M. Andrews, M.C. Catton, P.A. Lynch, J.A. Leydon, D.K. Gercovich, G.G. Hogg, M.L. Morgan and R.A. Lester, 2000. Enhanced measles surveillance during an interepidemic period in Victoria. Med. J. Aust., 172: 114.

23. Litt, M. and J. Waters, 1999. Update on the elimination of measles in Canada, 1998. Can. Commun. Dis. Rep., 25: 42.

24. Strebel, P.M., A.M. Henao-Restrepo, E. Hoekstra, J.M. Olive, M.J. Papania and S.L. Cochi, 2004. Global measles elimination efforts: the significance of measles elimination in the United States. J. Infect. Dis., 189 (Suppl. 1): S251.

25. Guris, D., R. Harpaz, S.B. Redd, N.J. Smith and M.J. Papania, 2004. Measles surveillance in the United States: An overview. J. Infect. Dis., 189 (Suppl. 1): S177.

26. Harpaz, R., M.J. Papania, K.E. Fujii, S.B. Redd, M.E. Wharton, S.C. Redd and J. Gindler, 2004. Lessons learned from establishing and evaluating indicators of the quality of measles surveillance in the United States, 1996-1998. J. Infect. Dis., 189 (Suppl. 1): S196.

27. Gay, N.J., G.De Serres, C.P. Farrington, S.B. Redd and M.J. Papania, 2004. Assessment of the status of measles elimination from reported outbreaks: United States, 1997-1999. J. Infect. Dis., 189 (Suppl. 1): S36. 